\title{
Synthesis and Characterization of Silsesquioxane-Based Polymer Hybrids with Controlled Structure
}

\author{
Ricardo O.R. Costa ${ }^{\mathrm{a}}$,Wander L. Vasconcelos ${ }^{\mathrm{a}}$ *and Richard M. Laine ${ }^{\mathrm{b}}$ \\ ${ }^{a}$ Department of Metallurgical and Materials Engineering, \\ Federal University of Minas Gerais, 30160-030 Belo Horizonte - MG, Brazil \\ ${ }^{\mathrm{b}}$ Departments of Materials Science and Engineering, \\ Chemistry and the Macromolecular Science and Engineering Center, \\ University of Michigan, 48109-2136 Ann Arbor - MI, USA
}

Received: September 27, 2001; Revised: July 10, 2002

\begin{abstract}
We have developed a method to obtain polymer hybrids with control of inorganic content and molecular configuration. Hybrid poly(methyl methacrylate) (PMMA) was obtained via atom transfer radical polymerization (ATRP) initiated by octafunctional cubic silsesquioxanes using $\mathrm{CuCl}$ as catalyst. Two different ATRP initiators obtained by attaching specific chemical groups to the cubic silsesquioxane were employed to produce two types of hybrids with different architectures. While $\alpha$-bromide ester groups generated a star-shaped polymer, the benzyl chloride groups produced longer and more linear polymeric chains containing the cubic silsesquioxane. These results were explained on the basis of the low initiation efficiency of benzyl chloride groups for PMMA, leading to polymers with molecular weights $\left(\mathrm{M}_{\mathrm{n}}\right)$ and polydispersities (PDI) higher than the expected ones.
\end{abstract}

Keywords: polymer hybrid, structural control, cubic silsesquioxane, ATRP

\section{Introduction}

In recent years, there have occurred major developments in the science and technology of polymeric materials with controlled architectures. In this sense, different kinds of regular branched polymers such as dendrimers, combs, ladders and stars have been designed ${ }^{1-3}$. The search for synthetic routes that lead to well-defined polymers aims to attain the control of structure-property relationships, so that the materials can be tailored for specific applications. Similarly, extensive efforts have been made to synthesize novel organic/inorganic hybrids from octahedral silsesquioxanes ${ }^{4-6}$, whose regular shape may also facilitate structural control of nanocomposite materials.

Branched molecules are particularly interesting due to their different processing characteristics and properties when compared to the linear molecules with the same molecular weight. Crystallinity, melting point, glass transition temperature, intrinsic viscosity and viscoelastic behavior are affected by branching 7 . The facility for processing branched polymers associated with the potential applications of organic-inorganic hybrid materials have stimulated the study of synthetic routes leading to block, graft and star polymers from inorganic macroinitiators 8 .

Although the concept of controlled/living polymerization processes has long been known ${ }^{9}$, only recent developments of controlled radical polymerization techniques ${ }^{10}$, particularly atom transfer radical polymerization (ATRP) ${ }^{11,12}$, allowed the synthesis of polymer hybrids with well-defined architectures and low polydispersities. In ATRP, the reaction is initiated by an alkyl halide activated by a catalyst, usually a complex of copper with a ligand, so that termination reactions are mostly suppressed because of a rapid equilibrium established between dormant and active propagating species.

In a previous paper ${ }^{13}$, we reported the synthesis of an 8-arm star poly(methyl methacrylate) (PMMA) via ATRP initiated by $\alpha$-bromide esters attached to an octafunctional silsesquioxane core. In the present study, the main concern is to investigate the effect of using the benzyl chloride group

*e-mail: wlv@demet.ufmg.br 
as initiator on the architecture of the polymer hybrids obtained.

\section{Experimental Section}

\section{Materials}

Syntheses of octakis(2-(4-chloromethylphenyl) ethyldimethylsiloxy) octasilsesquioxane (OCPS) and octakis(2-bromo-2-methylpropionoxypropyldimethylsiloxy)octasilsesquioxane (OBPS) have been reported elsewhere ${ }^{13}$. Methyl methacrylate (MMA) (99\% Acros) and acetonitrile (99.5\% Aldrich) were distilled under $\mathrm{N}_{2}$ and stored in flasks sealed under $\mathrm{N}_{2}$. $\mathrm{CuCl}$ (98\% Aldrich) was purified by stirring for $4 \mathrm{~h}$ with acetic acid, which dissolves $\mathrm{CuCl}_{2}$, washing the filtrate with ethanol and drying. The ligand $2,2^{2}-$ bipyridine (99\%) and the ATRP initiators, 4-methylbenzyl chloride (98\%) and ethyl-2-bromoisobutyrate (98\%), were used as received from Aldrich.

\section{General Procedure for the Solution ATRP of MMA}

In a typical reaction, $0.070 \mathrm{~g}(0.707 \mathrm{mmol})$ of $\mathrm{CuCl}$ and $0.329 \mathrm{~g}(2.10 \mathrm{mmol})$ of 2,2'-bipyridine were added to a $50 \mathrm{~mL}$ Schlenk flask, equipped with a reflux condenser and a magnetic stirrer. The reaction flask was degassed and purged $3 \times$ with $\mathrm{N}_{2}$. Acetonitrile $(15.0 \mathrm{~mL})$ and MMA ( $7.5 \mathrm{~mL}, 70.1 \mathrm{mmol}$ ) were added by syringe and the homogeneous solution formed was equilibrated in an oil bath at $90 \pm 2{ }^{\circ} \mathrm{C}$. In another small flask, OCPS initiator $(0.196 \mathrm{~g}$, $0.0877 \mathrm{mmol})$ was dissolved in acetonitrile $(7.5 \mathrm{~mL})$ under $\mathrm{N}_{2}$. The start of the reaction was recorded when the initiator was injected into the reaction flask. Samples of the reaction solution were collected at specific time intervals. A total of $\sim 4.0 \mathrm{~mL}$ of solution was collected each time by syringe and $2.5 \mathrm{~mL}$ was immediately poured into $20 \mathrm{~mL}$ of methanol to precipitate the polymer, which was washed with methanol to remove copper complex and then dried. The remaining $1.5 \mathrm{~mL}$ was used to determine monomer conversion by weighing the solution and the dried mass at $70{ }^{\circ} \mathrm{C}$ in a vacuum oven after mass change ceased.

\section{Characterization}

All analyses by gel permeation chromatography (GPC) were performed on a Waters 440 system, using an Acuflow Series III pump, Waters styragel columns $(7.8 \times 300$, HT2, $3,4)$ with RI detection using an Optilab DSP Interferometric Refractometer (Wyatt Technology). The system was calibrated using polystyrene standards, the eluent was $\mathrm{CH}_{2} \mathrm{Cl}_{2}$ and the flow was $1.0 \mathrm{~mL} / \mathrm{min}$.

\section{Results and Discussion}

The chemical structures of the octafunctional silsesquioxanes synthesized to be ATRP initiators are shown in
Scheme 1. For this kind of initiators, 8-arm star polymers are expected to be obtained in case all chemical groups initiate a propagating chain. Nevertheless, differences in the reactivity of each chemical group may influence the architecture of polymer hybrids obtained. For the purpose of comparison, OCPS and OBPS initiators were used to polymerize MMA under identical reaction conditions, i.e. equivalent concentrations of monomer, catalyst, ligand and initiator.

Figure 1 compares the dependence of the number-average molecular weight $\left(\mathrm{M}_{\mathrm{n}}\right)$ and polydispersity (PDI) on monomer conversion for PMMA hybrids obtained from both initiators, OCPS and OBPS. The drawn line represent the theoretical molecular weight, $\mathrm{M}_{\mathrm{n}(\mathrm{th})}$, calculated assuming that every initiator group originates only one polymer chain attached to the silsesquioxane core. It can be observed that, while $\mathrm{M}_{\mathrm{n}}$ for OBPS system is only slightly above the theoretical line, PMMA hybrids initiated by OCPS have much higher $\mathrm{M}_{\mathrm{n}}$. PDI values are also significantly higher for OCPS system, suggesting that polymerization is not controlled in this case.

Figure 2 shows the dependence of the parameter $\ln \left([\mathrm{M}]_{0} /[\mathrm{M}]\right)$ on reaction time, where $[\mathrm{M}]_{0}$ is the initial monomer concentration and $[\mathrm{M}]$ is the monomer concentration at a specific reaction time. In typical ATRP, the concentration of active species remains constant throughout the reaction, which can be verified by obtaining linear semilogarithmic plots of monomer conversion vs. time. Neither system presents such a linear dependence, meaning that the concentration of active species varies in both cases. In OCPS system, the upward concave curve indicates that additional

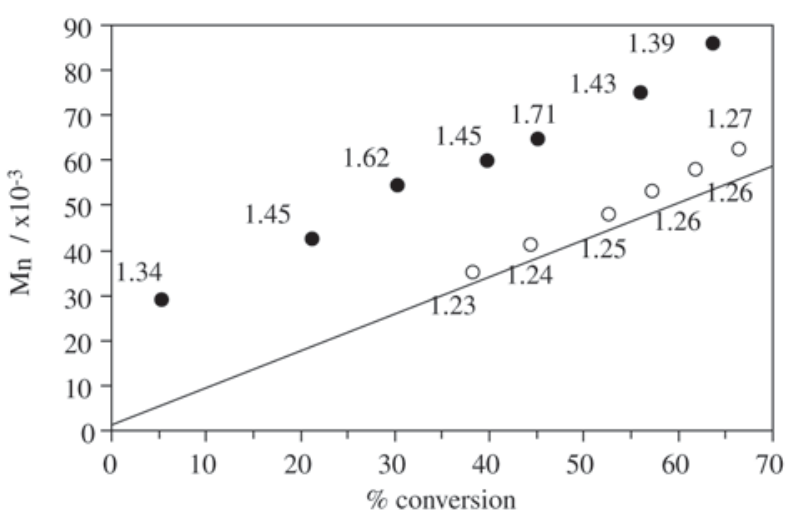

Figure 1. Comparison between the molecular weights of PMMA hybrids initiated by OCPS (filled) or OBPS (open) under similar reaction conditions. Line represents the theoretical $M_{n}$ for both studies and numbers are PDI values according to GPC. [initiator $]=2.92 \mathrm{mM},[\mathrm{CuCl}]=23.4 \mathrm{mM}, \mathrm{MMA}$ :initiator group $(-\mathrm{Cl}$ or $-\mathrm{Br})=100$. 

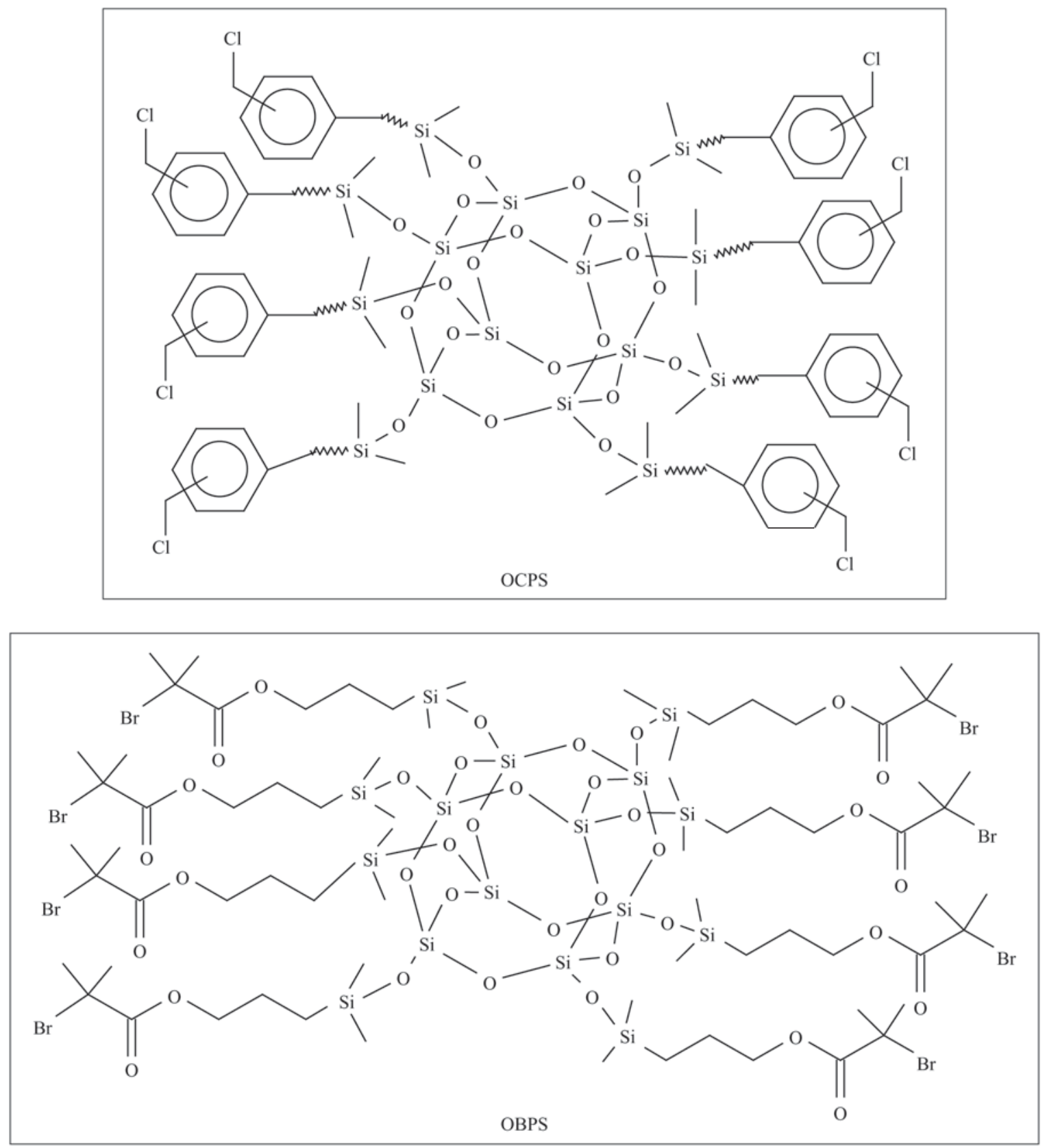

Scheme 1. Molecular structure of the ATRP initiators octakis(2-bromo-2-methylpropionoxypropyldimethylsiloxy)octasilsesquioxane (OBPS) and octakis(2-(4-chloromethylphenyl)ethyldimethylsiloxy)octasilsesquioxane (OCPS).

sites are activated throughout the reaction, contrary to OBPS system, whose downward concave curve suggests that propagating sites are deactivated as reaction proceeds.

The facts that OCPS initiator provides PMMA hybrids with $\mathrm{M}_{\mathrm{n}}$ higher than the predicted ones and the concentration of active species increases with time indicate that the benzyl chloride group does not actuate efficiently as ATRP initiator for MMA, confirming what has already been reported in the literature ${ }^{14}$. As a result, part of the initiating sites are inactive or even some OCPS molecules do not initiate polymer chains at all, the latter being more likely considering the high molecular weights achieved at the very beginning of the reaction. As reaction time increases, more initiating sites have the opportunity to be activated. The in- 


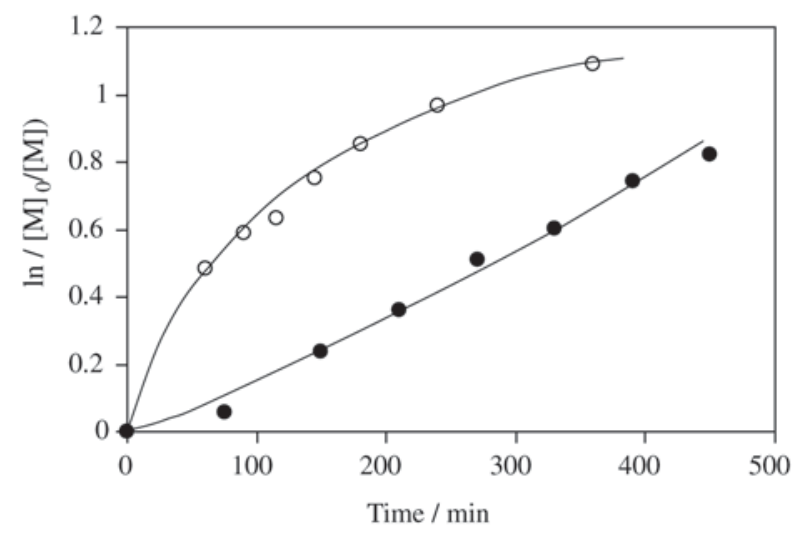

Figure 2. Semi-logarithmic kinetic plot for the synthesis of PMMA hybrids initiated by OCPS (filled) or OBPS (open) under similar reaction conditions. Lines are used only to guide the eye. [initiator $]=2.92 \mathrm{mM},[\mathrm{CuCl}]=23.4 \mathrm{mM}$, MMA:initiator group $(-\mathrm{Cl}$ or $-\mathrm{Br})=100$.

creasing concentration of propagating chains as reaction proceeds increases polydispersity, as observed in Fig. 1. However, the steric hindrance caused by grown polymer chains would probably impede the access of monomer to most of the remaining inactive initiating groups on the core. The apparent tendency for decreasing PDI at higher conversions might result from the lower propagating rates of longer chains associated with the activation of non-reacted OCPS molecules and a few accessible non-reacted initiating sites.

On the other hand, the higher reaction rates provided by OBPS initiator (Fig. 2) mean that virtually all OBPS molecules and a significant fraction of its $8 \alpha$-bromide esters initiating groups are active as propagating polymer chains. Moreover, their $\mathrm{M}_{\mathrm{n}}$ close to the theoretical ones (Fig. 1) and their comparatively low PDI values suggest that a star PMMA has been formed. However, the decreasing concentration of active species demonstrated in Fig. 2 is indicative of the occurrence of inevitable termination reactions that lead to coupling between star molecules. Termination reactions promote deactivation of propagating sites and consequent stabilization of catalyst in its oxidized form $\mathrm{CuX}_{2}$, leading to a downward concave curve.

The confirmation that coupling takes place between stars initiated by OBPS but not by OCPS can be observed in Fig. 3, where GPC traces for both systems are compared. The pairs of curves refer to samples with similar monomer conversions. As already discussed, OCPS produces higher $\mathrm{M}_{\mathrm{n}}$ polymer hybrids, but more important is the high molecular weight shoulder that appears in OBPS samples and increases with conversion. This shoulder results probably from the presence of double or even higher order stars

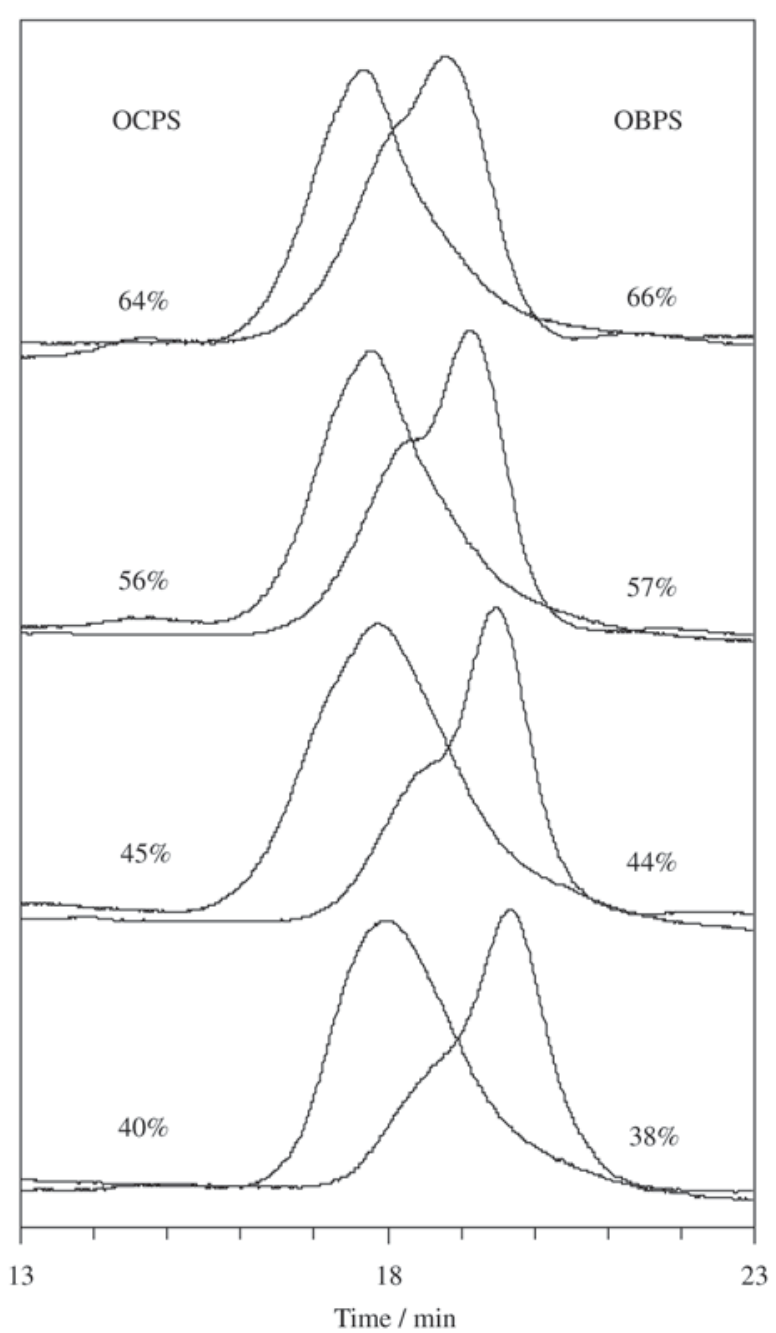

Figure 3. GPC traces of PMMA hybrids initiated by OCPS or OBPS and obtained under similar reaction conditions with approximate the same monomer conversions. [initiator] $=2.92 \mathrm{mM}$, $[\mathrm{CuCl}]=23.4 \mathrm{mM}$, MMA:initiator group $(-\mathrm{Cl}$ or $-\mathrm{Br})=100$.

formed when coupling takes place between arms of different star molecules. The high concentration of active sites in OBPS system, caused by the efficient initiation of $\alpha$-bromide ester groups, increases the probability for termination reactions to occur as compared with OCPS system. If termination occurs by disproportionation, unsaturated chain ends may be formed and further linked to other propagating arms, while termination by combination would lead to direct star-star coupling.

In order to determine the number of arms attached to each core, polymer hybrids were reacted with HF so that the silsesquioxane structure was cleaved. By comparing the molecular weights of the hybrids with those of the liberated 
arms, the number of arms could be determined. The applied procedure to OBPS system has been better described elsewhere ${ }^{13}$. An average of 6.5 arms was found for OBPSinitiated hybrid, while OCPS-initiated hybrids had only 2 arms at high monomer conversions.

To confirm the hypothesis of initiator inefficiency, another experiment was carried out using the ATRP initiators 4-methylbenzyl chloride $(\mathrm{BzCl})$ and ethyl-2-bromoisobutyrate $(\mathrm{BrBu})$, which are small molecules containing the same chemical groups previously attached to the cubes. The comparison between results obtained using the initiator cubes and those obtained using $\mathrm{BzCl}$ and $\mathrm{BrBu}$ would permit the evaluation of any possible influence or steric effect caused by the presence of the cubic silsesquioxane. Figure 4 shows the dependence of $\mathrm{M}_{\mathrm{n}}$ on monomer conversion for ATRP of MMA initiated by both $\mathrm{BzCl}$ and $\mathrm{BrBu}$. It can be noted that the $\mathrm{M}_{\mathrm{n}}$ of PMMA initiated by $\mathrm{BrBu}$ follows its theoretical line very closely, whereas the $M_{n}$ of PMMA initiated by $\mathrm{BzCl}$ is almost $10 \times$ higher than expected at low conversions, similarly to what has been found for OCPS and OBPS systems. Also, PDI values are considerably higher for $\mathrm{BzCl}$ system, confirming that late initiation takes place.

Figure 5 shows the dependence of the parameter $\ln \left([\mathrm{M}]_{0} /[\mathrm{M}]\right)$ on reaction time. The results obtained for $\mathrm{BzCl}$ and $\mathrm{BrBu}$ are very similar to those obtained for OCPS and OBPS systems (Fig. 2). Even though the $\mathrm{BzCl}$ concentration employed was twice as much as the $\mathrm{BrBu}$ one, the reaction was still slower, confirming that benzyl chloride group does not initiate efficiently MMA polymerization. There-

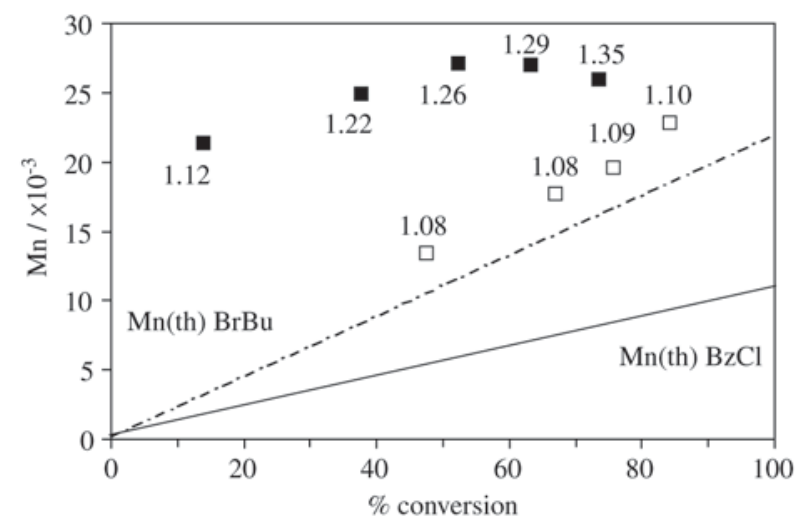

Figure 4. Dependence of $M_{n}$ on monomer conversion of linear PMMA initiated by 4-methylbenzyl chloride (BzCl) (filled) or ethyl-2-bromoisobutyrate $(\mathrm{BrBu})$ (open). Lines represent the theoretical $\mathrm{M}_{\mathrm{n}}$ for eachh study and numbers are PDI values according to $\mathrm{GPC}$. $[\mathrm{BzCl}]=2.92 \mathrm{mM},[\mathrm{CuCl}]=23.4 \mathrm{mM}, \mathrm{MMA}: \mathrm{BzCl}=100$; $[\mathrm{BrBu}]=1.46 \mathrm{mM},[\mathrm{CuCl}]=11.7 \mathrm{mM}, \mathrm{MMA}: \mathrm{BrBu}=200$. fore, ATRP initiated by silsesquioxanes is virtually not affected in its fundamental aspects.

ATRP was found to be suitable for the synthesis of thermoplastic PMMA hybrids from octafunctional cubic silsesquioxanes. This would not be possible via conventional free radical polymerization without forming a gelled network. Furthermore, the hybrid structure was found to be dependent on the type of initiator group, more specifically its initiating efficiency. As depicted in Scheme 2, PMMA hybrid initiated

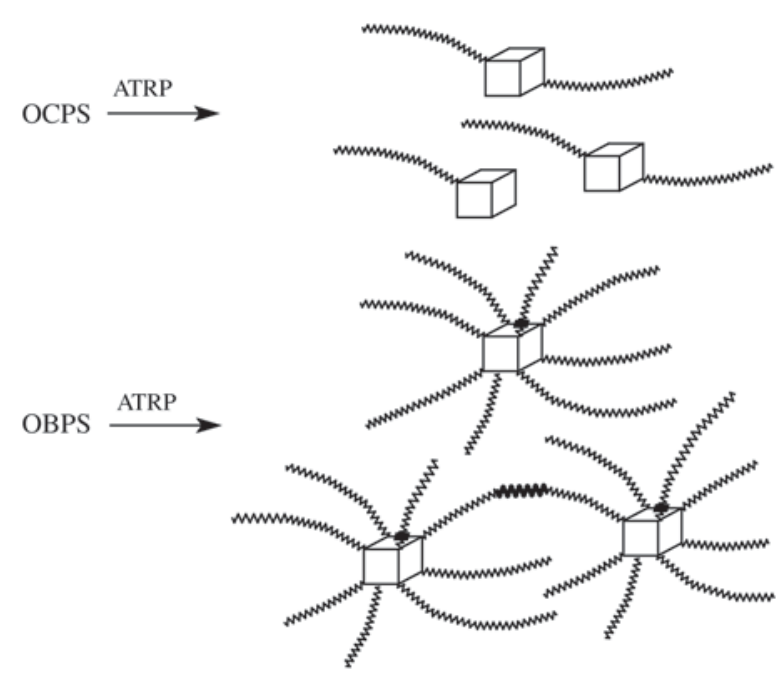

Scheme 2. Molecular architecture of PMMA hybrids initiated by OCPS and OBPS.

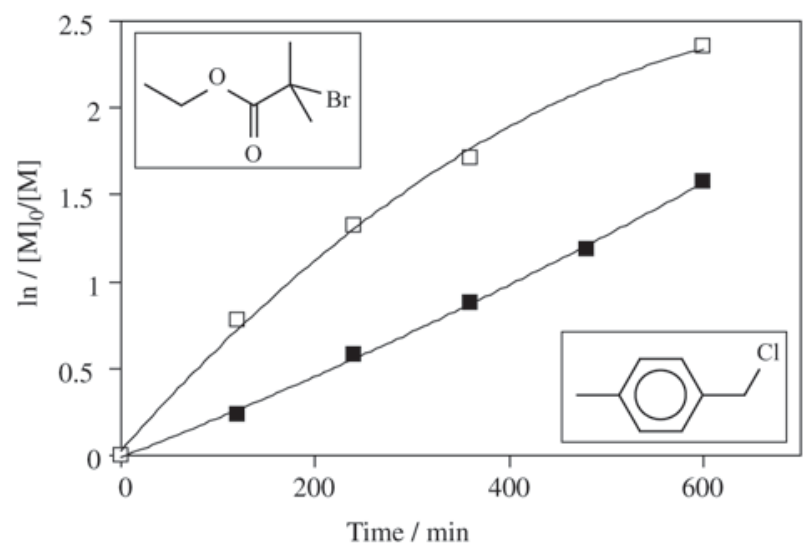

Figure 5. Semi-logarithmic kinetic plot for the synthesis of linear PMMA initiated by 4-methylbenzyl chloride (BzCl) (filled) or ethyl-2-bromoisobutyrate $(\mathrm{BrBu})$ (open). Lines are used only to guide the eye. $[\mathrm{BzCl}]=2.92 \mathrm{mM},[\mathrm{CuCl}]=23.4 \mathrm{mM}$, MMA: $\mathrm{BzCl}=100 ;[\mathrm{BrBu}]=1.46 \mathrm{mM},[\mathrm{CuCl}]=11.7 \mathrm{mM}$, $\mathrm{MMA}: \mathrm{BrBu}=200$. 
by OBPS is a star-type polymer with a small fraction of coupled arms, while the OCPS initiated PMMA hybrid contains more linear molecules due to the inactivity of most initiating sites. In both cases, inorganic content can be controlled by changing molecular weight and structural control can be assessed by choosing either OBPS or OCPS initiators or even a combination of them in a specific proportion.

\section{Conclusions}

By employing different octafunctional ATRP initiators, OCPS and OBPS, PMMA hybrids with different molecular architectures were obtained. Given the low initiation efficiency of benzyl chloride groups for ATRP of methyl methacrylate, it was obtained a polymer hybrid with an average of only 2 polymer chains attached to OCPS core. However, star-shaped molecules were obtained when OBPS initiator was employed. The different molecular architectures serve as a basis for structural control of polymer hybrids. The polymerization characteristics of the silsesquioxane-based polymer hybrids are quite similar to those of their linear analogues generated from the unattached ATRP initiators. Therefore, the activity of the initiating groups remained virtually unaffected by their attachment to the silsesquioxane core, which is an important conclusion for further studies involving different initiators.

\section{Acknowledgements}

The authors gratefully acknowledge the financial support from CAPES, FAPEMIG and CNPq (Brazil) and the partial support from Pfizer and the Air Force Phillips Laboratories at Edwards Air Force Base for aspects of these studies.

\section{References}

1. Quirk, R.P.; Lee, Y.; Kim, J. in Star and Hyperbranched Polymers, M.K. Mishra and S. Kobayashi, Eds., Marcel Dekker, New York, p. 13, 1999.

2. Hadjichristidis, N.; Pispas, S.; Pitsikalis, M.; Iatrou, H.; Vlahos, C. Adv. Polym. Sci., v. 142, p. 71-127, 1999.

3. Webster, O. Science, v. 251, p. 887-893, 1991.

4. Laine, R.M.; Zhang, C.; Sellinger, A.; Viculis, L. Appl. Organometal. Chem., v. 12, p. 715-723, 1998.

5. Choi, J.; Costa, R.O.R.; Tamaki, R.; Laine, R.M. Polym. Prep., ACS Div. Polym. Chem., v. 41, n.1, p. 524-525, 2000.

6. Laine, R.M.; Choi, J.; Lee, I. Adv. Mater., in press.

7. Roovers, J. in Encyclopedia of Polymer Science and Engineering, 2nd ed., J.I. Kroschwitz, Ed., Wiley, New York, v. 2, p. 478, 1985.

8. Matyjaszewski, K.; Miller, P.J.; Fossum, E.; Nakagawa, Y. Appl. Organometal. Chem., v. 12, p. 667-673, 1998.

9. Szwarc, M. Nature, v. 178, p. 1168-1169, 1956.

10. Mishra, M.K.; Yagci, Y. in Handbook of Radical Vinyl Polymerization, Marcel Dekker, New York, p. 233, 1998.

11. Wang, J.-S.; Matyjaszewski, K. J. Am. Chem. Soc., v. 117, p. 5614-5615, 1995.

12. Wang, J.-S.; Matyjaszewski, K. Macromolecules, v. 28, p. 7901-7910, 1995.

13. Costa, R.O.R.; Vasconcelos, W.L.; Tamaki, R.; Laine, R.M. Macromolecules, v. 34, p. 5398-5407, 2001.

14. Matyjaszewski, K.; Shipp, D.A.; Wang, J.-L.; Grimaud, T.; Patten, T.E. Macromolecules, v. 31, p. 6836-6840, 1998. 